\title{
Новые исследования на городище Бытыгай
}

\section{(c) 2021 г. Сакенов С.К., Бурбаева С.Б., Букешева Г.К., Кукушкин А.И.}

Keywords: archaeology, medieval urban culture, settlement of Bytygay, mausoleum, production workshop, fired and terracotta bricks, glaze

Түйін сөздер: археология, ортағасырлық қала мәдениеті, Бытығай қаласы, кесене, өндіріс цехы, күйдірілген және терракоталық кірпіш, глазурь

Ключевые слова: археология, средневековая городская культура, городище Бытыгай, мавзолей, производственный цех, обожженные и терракотовые кирпичи, глазурь

\section{Sergazy Sakenov' ${ }^{1}$, Saule Burbaeva², Gulzat Bukesheva², Alexei Kukushkin ${ }^{3}$}

${ }^{1}$ Corresponding author, Doctor of Philosophy (PhD), Branch of the A.Kh. Margulan Archaeology Institute in Nur-Sultan, Nur-Sultan, Kazakhstan. E-mail: sergazi 82@mail.ru

${ }^{2}$ Candidate of Pedagogical Sciences, Director, State Historical and Cultural

Museum-Reserve “Bozok”, Nur-Sultan, Kazakhstan. E-mail: rgkpbozok@gmail.com

${ }^{2}$ Master of Humanities, Junior Researcher, State Historical and Cultural Museum-Reserve

"Bozok", Nur-Sultan, Kazakhstan. E-mail: rgkpbozok@gmail.com

${ }^{3}$ Doctor of Philosophy (PhD), E.A. Buketov Karagandy State University, Karagandy, Kazakhstan. E-mail: sai@ksu.kz

\section{New research in the city of Bytygay}

\begin{abstract}
The article presents the preliminary results of the archaeological excavations of the medieval settlement of Bytygay, carried out in the field season of 2021. The settlement is located on the left bank of the Nura River, $1 \mathrm{~km}$ east of the village of Korgalzhin, Korgalzhinsky district, Akmola region. Two excavations were laid on the territory of the monument. The area of the first excavation was $200 \mathrm{~m}^{2}$, the area of the second $-120 \mathrm{~m}^{2}$. The production hall has been fully investigated, which includes two furnaces for melting glaze, a kiln for firing bricks, as well as a facility for preliminary drying of raw bricks. The paper gives the main characteristics of the fixed objects and building materials. As a result of the archaeological excavations of the production workshop, six types of fired bricks were revealed, one type with an ornament without glaze and one type ornamented, covered with glaze. The research materials show the level of development of urban culture in the Tengiz-Korgalzhin region and indicate that Bytygay, along with other famous medieval settlements, was an administrative and commercial center located at the intersection of caravan routes. The production workshop for the manufacture and firing of bricks and architectural and finishing materials is dated presumably by 14 th-15th centuries.
\end{abstract}

Acknowledgement: The publication was prepared within the framework of program-targeted financing of the Committee of Culture of the Ministry of Culture and Sports of the Republic of Kazakhstan, IRN of the project is BR10164212.

For citation: Sakenov S., Burbaeva S., Bukesheva G., Kukushkin A. New research in the city of Bytygay. Kazakhstan Archeology. 2021, 4 (14), 134-147 (in Russian). DOI: 10.52967/akz2021.4.14.134.147 


\title{
Сәкенов Серғазы ${ }^{1}$, Бөрібаева Сәуле 2 , Букешева Гүлзат ${ }^{2}$, Кукушкин Алексей ${ }^{3}$
}

${ }^{1}$ автор-корреспондент, философия докторы (PhD), Нұр-Сұлтан қаласындағы

A.X. Марғұлан атындағы Археология институтының филиалы,

Нұр-Сұлтан, Қазақстан. E-mail: sergazi_82@mail.ru

${ }^{2}$ педагогика ғылымдарының кандидаты, директор, «Бозоқ» мемлекеттік тарихи-

мәдени қорық-музей, Нұр-Сұлтан, Қазақстан. E-mail: rgkpbozok@gmail.com

${ }^{2}$ Археология және этнология ғылымдарының магистрі, кіші ғылыми қызметкер,

«Бозоқ» мемлекеттік тарихи-мәдени қорық-музей, Нұр-Сұлтан, Қазақстан.

E-mail:rgkpbozok@gmail.com

${ }^{3}$ философия докторы (PhD), Е.А. Бөкетов атындағы Қарағанды мемлекеттік университеті, Қарағанды, Қазақстан.. E-mail: sai@ksu.kz

\section{Бытығай қалашығындағы жаңа зерттеулер}

\begin{abstract}
Аннотация. Мақалада 2021 жылғы далалық маусымда жүргізілген Бытығай ортағасырлық қалашығындағы археологиялық қазба жұмыстарының алдын ала қорытындылары келтірілген. Қалашық Ақмола облысы Қорғалжын ауданы, Қорғалжын ауылынан шығысқа қарай 1 км жерде, Нұра өзенінің сол жақ жағалауында орналасқан. Ескерткіш аумағында екі қазба жұмыс алаңы бекітіліп, археологиялық қазба жұмыстары жүргізілді. Бірінші қазба алаңының ауданы $200 \mathrm{~m}^{2}$, екіншісінің ау-

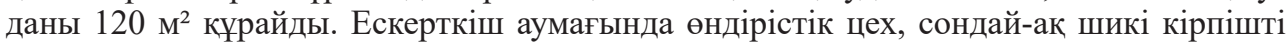
алдын ала кептіруге арналған құрылыстар толық зерттелген. Жұмыста тіркелген нысандар мен құрылыс материалдарының негізгі сипаттамасы берілген. Өндірістік цехта жүргізілген археологиялық қазба жұмыстарының нәтижесінде күйдірілген кірпіштің алты түрі, кірпіш бетті жылтырақ шыны әшекеймен қапталған бір түрі және әшекейсіз оюланған кірпіштердің бір түрі тіркелді. Жүргізілген жұмыстардың нәтижелері ТеңізҚорғалжын өңіріндегі қала мәдениетінің даму деңгейін көрсетеді және Бытығайдың басқа да ортағасырлық белгілі қалашықтармен қатар керуен маршруттарының қиылысында орналасқан әкімшілік-сауда орталығы болғандығын айғақтайды. Кірпіш пен сәулет-әрлеу материалдарын дайындау және күйдіру жөніндегі өндірістік цех шамамен XIV-XV ғасырларға белгіленген.
\end{abstract}

Алғыс: Жарияланым Қазақстан Республикасы Мәдениет және спорт министрлігі Мәдениет комитетінің бағдарламалық-нысаналы қаржыландыруы, ЖTH BR10164212 жобасы шеңберінде дайындалды.

Сілтеме жасау үшін: Сәкенов С., Бөрібаева С., Букешева Г., Кукушкин А. Бытығай қалашығындағы жаңа зерттеулер. Қазақстан археологиясы. 2021. № 4 (14). 134-147-бб. (Орысша). DOI: 10.52967/akz2021.4.14.134.147

\section{Сакенов Сергазы Кайырбекович ${ }^{1}$ Бурбаева Сауле Букихановна ${ }^{2}$, Букешева Гульзат Кайнулловна ${ }^{2}$, Кукушкин Алексей Игоревич ${ }^{3}$}

${ }^{1}$ автор-корреспондент, доктор философии (PhD), Филиал Института археологии им. А.Х. Маргулана в г. Нур-Султан, Нур-Султан, Казахстан.

E-mail: sergazi_82@mail.ru

${ }^{2}$ кандидат педагогических наук, директор, Государственный историко-культурный музей-заповедник «Бозок», г. Нур-Султан, Казахстан. E-mail: rgkpbozok@,gmail.com

${ }^{2}$ магистр гуманитарных наук, младший научный сотрудник, Государственный историко-культурный музей-заповедник «Бозок», г. Нур-Султан, Казахстан.

E-mail: rgkpbozok@gmail.com

${ }^{3}$ доктор философии (PhD), Карагандинский университет имени Е.А. Букетова, г. Караганды, Казахстан. E-mail: sai@ksu.kz 
Аннотация. В статье приведены предварительные итоги археологических раскопок средневекового городища Бытыгай, проведенных в полевом сезоне 2021 г. Памятник находится на левом берегу р. Нура, в 1 км к востоку от села Коргалжин (Коргалжинский p-н, Акмолинская обл.). На территории городища были заложены два раскопа. Площадь первого раскопа составила $200 \mathrm{M}^{2}$, площадь второго - $120 \mathrm{M}^{2}$. Полностью исследован производственный цех, включающий две печи для плавки глазури, печь для обжига кирпичей, а также сооружение, предназначенное для предварительной сушки сырого кирпича. В работе дается основная характеристика зафиксированных объектов и строительных материалов. В результате раскопок производственного цеха выявлено несколько типов кирпичей: шесть - обожженных кирпичей, один - с орнаментом без глазури и один тип - орнаментированный, покрытый глазурью. Материалы исследования показывают уровень развития городской культуры в Тенгиз-Коргалжинском регионе и свидетельствуют о том, что Бытыгай, наряду с другими известными средневековыми городищами, являлся административно-торговым центром, расположенным на пересечении караванных маршрутов. Производственный цех по изготовлению и обжигу кирпичей и архитектурно-отделочных материалов датирован предположительно XIV-XV вв.

Благодарности: Публикация подготовлена в рамках программно-целевого финансирования Комитета культуры Министерства культуры и спорта Республики Казахстан, ИРН проекта BR10164212.

Для цитирования: Сакенов С.К., Бурбаева С.Б., Букешева Г.К., Кукушкин А.И. Новые исследования на городище Бытыгай. Археология Казахстана. 2021. № 4 (14). С. 134 147. DOI: $10.52967 / \mathrm{akz} 2021.4 .14 .134 .147$

\section{Введение}

Изучение городской культуры в степном регионе Казахстана является одним из актуальных направлений в отечественной археологии. В рамках данной проблемы перспективным регионом для проведения комплексных исследований является Сарыарка, на территории которой зафиксировано множество памятников историкокультурного наследия [Свод памятников... 2009].

Городище Бытыгай находится на левом берегу р. Нура, в 1 км к востоку от села Коргалжин (Коргалжинский район, Акмолинская обл.) (рис. 1). Первые сведения о нем появляются в путевых записках и публикациях российских путешественников и ученых еще в XVIII в. [Шангин 1820; Броневский 1830: 244-252; Бурбаева и др. 2021: 136-141]. В ранних нарративных источниках, более полно

описывающих памятник, он обычно обозначается как мавзолей Бытыгай. Согласно этим данным, мавзолей портально-купольного типа возведен из обожженных кирпичей, а в оформлении портальной части использовались резные терракотовые кирпичи.

Первые археологические раскопки данного культового сооружения на территории городища Бытыгай были предприняты ЦентральноКазахстанской археологической экспедицией (ЦКАЭ) под руководством А.Х. Маргулана. В 1974 г. на территории городища отдельным коргалжинским отрядом ЦКАЭ были проведены раскопки на месте скопления развалин, в том числе было тщательно исследовано поминально-культовое сооружение размерами $21 \times 17,4$ м. Среди массы обожженных кирпичей разных размеров можно выделить терракото- 


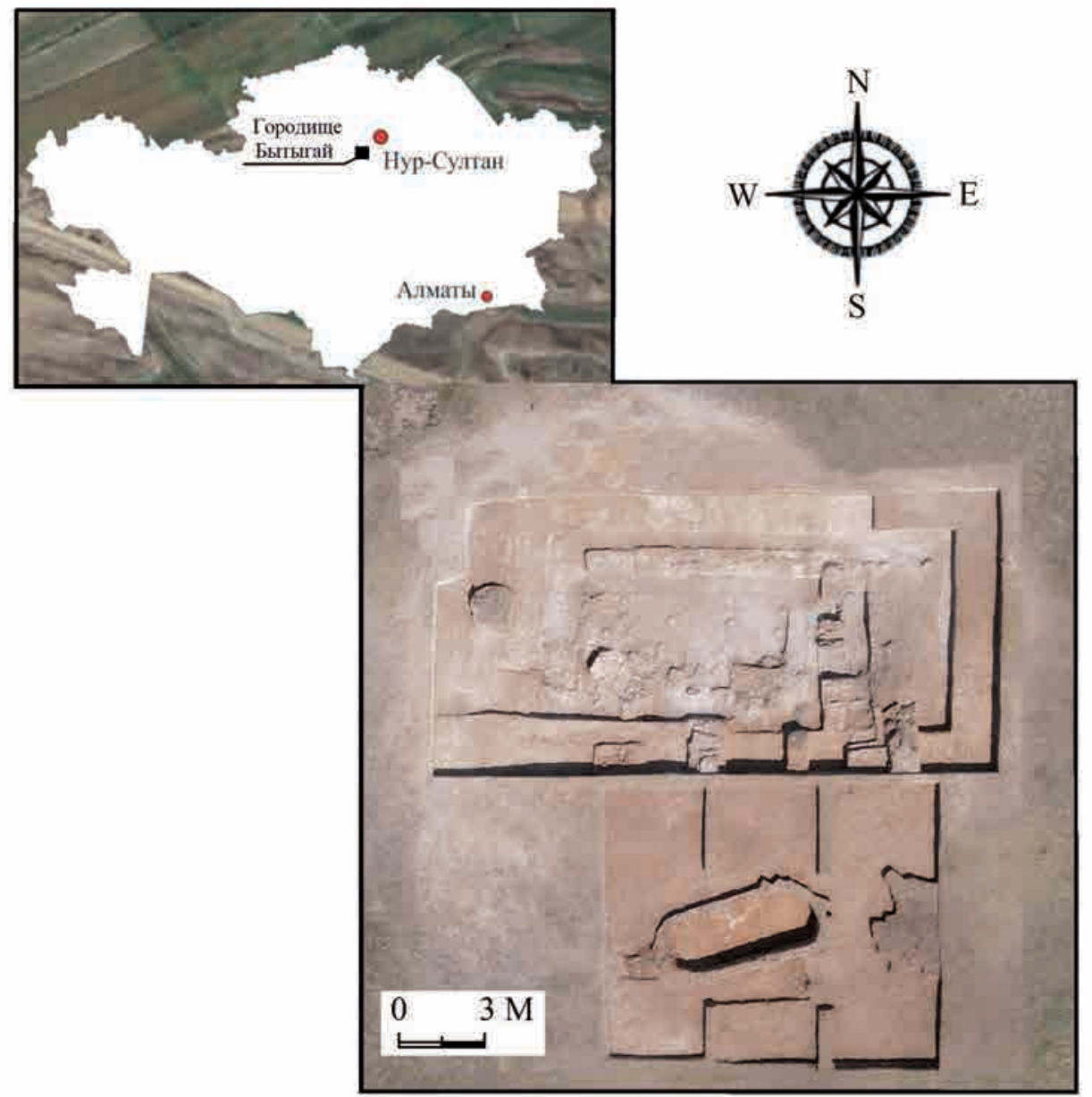

Рис. 1. Городище Бытыгай на карте Казахстана и фото раскопа 1-сур. Қазақстан картасындағы Бытығай қаласы және қазба суреті

Fig. 1. The ancient settlement Bytygay on the map of Kazakhstan and a photo of the excavation site

вые сталактиты с растительным орнаментом и единичные экземпляры фрагментов и обломков кирпичей со знаками султанской тамги [Маргулан 1950: 4-13; Сембин 1975: 21]. Опираясь на полученные данные о размерах и плане мавзолея, изучив строительные приемы и декор кирпичей, А.X. Маргулан датировал памятник X-XII вв. [Архивные отчеты... 1975].

После долгого перерыва в 2000 г. на территории городища были возобновлены археологические изыскания под руководством М.Е. Елеуова. Методом сплошного раскопа был исследован круглый в плане холм диаметром 30 м, высотой 1,2 м. Холм окружен у подножия рвом шириной 3 м, глубина в разных местах составляла от 0,3 до 1 м. После снятия первого слоя грунта была расчищена ограда, выложенная из рваного камня. Ширина каменной кладки составляла 2-2,5 м. Во внутреннем пространстве 
ограды расчищены остатки сооружения, которое представляло собой выкладку из обожженных кирпичей, ориентированную по линии север-юг. Площадь кирпичной кладки (длина 24 м, ширина 23 м) составляет 552 м². После вскрытия пола сооружения в восточной части строения обнаружены две могильные ямы. В погребении № 1 скелет лежал на правом боку, руки находились вдоль туловища, ноги вытянуты, головой ориентирован на север, лицом на запад. Погребение безынвентарное. В захоронении № 2 у погребенного руки и ноги согнуты, головой ориентирован на север, лицом на запад. В изголовье найден костяной гребень. При расчистке склепов среди обожженных кирпичей найден кирпич размерами $22,5 \times 22,5 \times 4$ см, на поверхности которого имеется знак родовой тамги в виде двух кругов «ОО» [Елеуов 2000: 12].

Необходимо акцентировать внимание на еще одном сооружении, которое было исследовано в том же году. В восточной части раскопа на возвышенном месте находился объект круглой в плане формы диаметром 2 м. Его стенки возведены из природного камня. Конструкция имела вход с южной стороны. После расчистки внутреннего пространства от грунта на полу был зафиксирован обгоревший слой плетеного камыша мощностью 0,2 м. Как отмечает руководитель раскопок, сооружение прекратило свое функционирования после сильного пожара. М.Е. Елеуов рассматривает данный объект как руины караульного здания, а весь памятник как важное строение, стоящее на перекрестке караванных дорог [Елеуов 2000: 18].

В 2006-2009 гг. на территории городища Бытыгай отдельный от- ряд РГП «Казреставрация» провел археологические раскопки под руководством М. Семби. В ходе работы были изучены развалы мавзолея и кирпичеобжигательной печи, получены новые материалы. Основываясь на совокупных данных археологических материалов, авторы раскопок датируют исследуемые объекты XV-XVI вв. [Семби 2015: 153]. Далее, базируясь на результатах археологических раскопок и анализе архивных данных, специалисты РГП «Казреставрация» в 2012 г. сделали научную реконструкцию мавзолея и воссоздали его на территории городища.

\section{Характеристика нового мате-} риала

В 2021 г. исследования на территории городища Бытыгай были продолжены научными сотрудниками РГКП «Государственный историкокультурный музей-заповедник "Бозок”» Министерства культуры и спорта Республики Казахстан. Археологические раскопки проведены на объекте, находящемся в 70 м к северозападу от реконструированного мавзолея. Сооружение представляло собой котлован овальной в плане формы размерами $8 \times 12$ м, ориентированный по линии запад-восток. С южной стороны котлована на поверхности земли обнаружена кирпичная кладка. Для всестороннего охвата объекта заложены два раскопа: площадь первого раскопа составляет $200 \mathrm{~m}^{2}$, второго $120 \mathrm{M}^{2}$ (рис. 2).

Предварительнье результать раскопок производственного ичентра

Фундамент сооружения зафиксирован на глубине 0,9 м от современной поверхности земли. Он имел прямоугольную форму размерами 


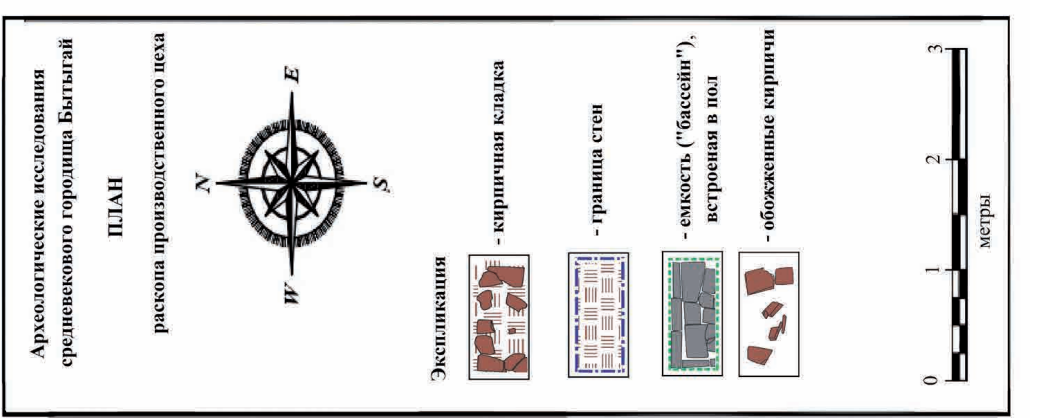

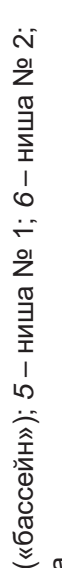

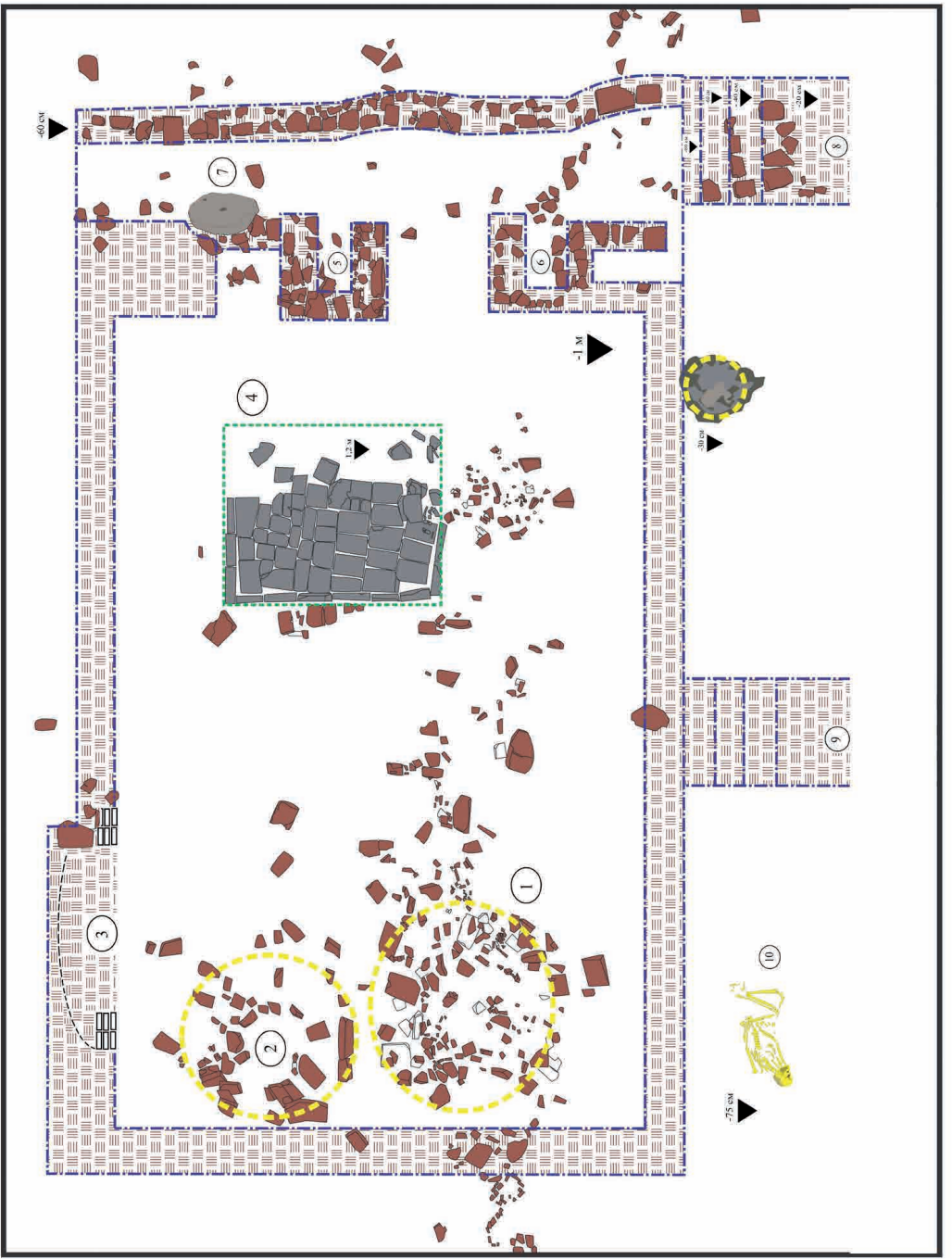

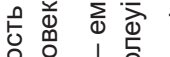

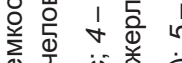

元

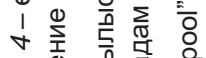

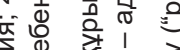

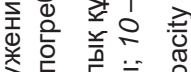

응

엉구 夌

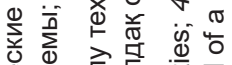

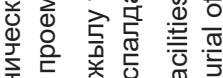

王

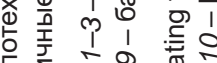

들 至

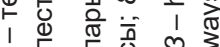

2)

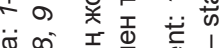

खंख

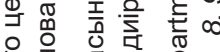

우윯잉

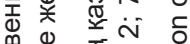

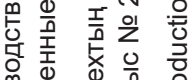

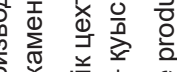

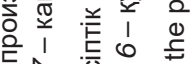

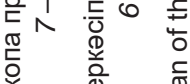

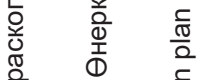

필

ᄃ

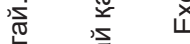

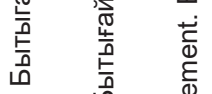

寻 它

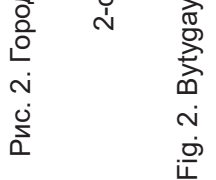


$10,2 \times 6$ м, длинной осью ориентирован с запада на восток. Здание состоит из двух помещений, разделенных стеной из обожженных кирпичей. Две комнаты соединены между собой проходом. В восточной части расположено малое помещение $(0,9 \times 5,7$ м), в западной - большое (6×7,8 м).

Малое помещение имеет прямоугольную форму. Хорошо сохранились внешняя восточная стена и внутренняя стена, отделяющая одну комнату от другой. Вход в помещение осуществлялся с южной стороны через лестничную конструкцию (рис. 2, 8). Основа ступенек сделана из материкового останца, а затем обложена обожженными кирпичами. В стене, разделяющей помещения, имеется проем шириной 0,9 м, заполненный слоем золы мощностью 0,3 м. Также в стене с обеих сторон возле прохода сделаны ниши: правая размерами $0,3 \times 0,6$ м (рис. 2, 5), левая $-0,4 \times 0,6$ м (рис. 2, 6).

В южной стене большого помещения по центру зафиксирован проем шириной 1 м, здесь же расчищен лестничный проход, уцелели четыре ступеньки из материкового останца, которые были обложены кирпичами (рис. 2, 9). С восточной стороны от центрального входа в большой комнате на глубине -1 м от уровня современной поверхности в полу был устроен «бассейн». В плане конструкция имела квадратную форму размерами $2,1 \times 1,8$ м, глубиной 0,2 м (рис. 2, 4). Емкость предназначалась для отмачивания ганча и других смесей, которые в последующем использовались в производстве глазури.

В западной части помещения расчищены развалы нескольких печных сооружений. Первая печь устрое- на в юго-западном углу. В плане она круглой формы диаметром 1,5 м. В устье печи имелось скопление сажи, золы и обугленных дров. Вторая печь находилась в северо-западном углу. Она круглой в плане формы диаметром 0,8 м. Сохранилась кладка основания печи. Разрез и развал стен свидетельствуют о том, что печь была открытого типа (рис. 2, 2). Скорее всего, она предназначалась для плавки глазури. Третья печь каминного типа расположена ближе к северо-западному углу. Судя по всему, она использовалась для обжига кирпичей. Длина ее составляла 2,4 м, однако уцелела только нижняя часть (рис. 2, 3). Coгласно анализу профилей, печь имела два уровня: нижний - топка, верхний уровень со сводчатым перекрытием - камера для обжига. В профиле северных линий бровок зафиксированы два пятна круглой формы диаметром 0,15 м, расстояние между ними составляет 1,2 м. Вероятно, это следы горизонтальных дымоходов.

За пределами южной стены сооружения на глубине 0,73 м расчищено погребение человека. Скелет лежал на спине, головой ориентирован на запад, лицом на юг. Руки вытянуты вдоль тела, ноги согнуты и повернуты на юг. Погребение безынвентарное (рис. 2, 10).

С южной стороны от данного раскопа была зафиксирована кладка из обожженных кирпичей. После снятия первого слоя грунта и зачистки выявлено сооружение овальной формы, его длина равна 6,3 м, ширина 2,7 м. Сооружение ориентировано по длинной оси в направлении запад-восток (рис. 1). Внешняя стена выложена кладкой в два ряда. Центральная часть также заполнена несколькими рядами кладки. После дальнейшей расчистки 
и углубления обнаружена пристроенная с западной стороны теплотехническая конструкция прямоугольной в плане формы длиной 0,9 м, шириной 0,7 м. При расчистке на месте их стыка отмечены следы прокала по всей стенке. Во внутренней части печи зафиксировано скопление золы, сажи и обугленных дров.

На противоположенной восточной стене фиксируется пятно круглой формы, заполненное переотложенным грунтом; вероятно, это место прохода горизонтального дымохода. За пределами южной стены конструкции на уровне -0,4 м расчищены плохо сохранившиеся кости ребенка. Обнаружены лишь часть черепа, ребра и берцовые кости.
За пределами данного сооружения в северо-восточной части, в квадрате E/3 на ровной площадке найден in situ целый керамический сосуд. По форме это амфора с ручкой и со сливом. Сосуд был плотно закрыт кирпичом и закопан в землю. Благодаря хорошей консервации, предохранившей от порчи и разрушения, внутри сосуда сохранилась жидкость темного цвета, густой консистенции (рис. 3,1$)$.

На основании изложенного можно сделать однозначный вывод о том, что данная конструкция предназначалась для сушки сырого кирпича. В результате проведенных археологических раскопок производственного цеха выявлены шесть типов обожженных кирпичей, один тип с орнаментом

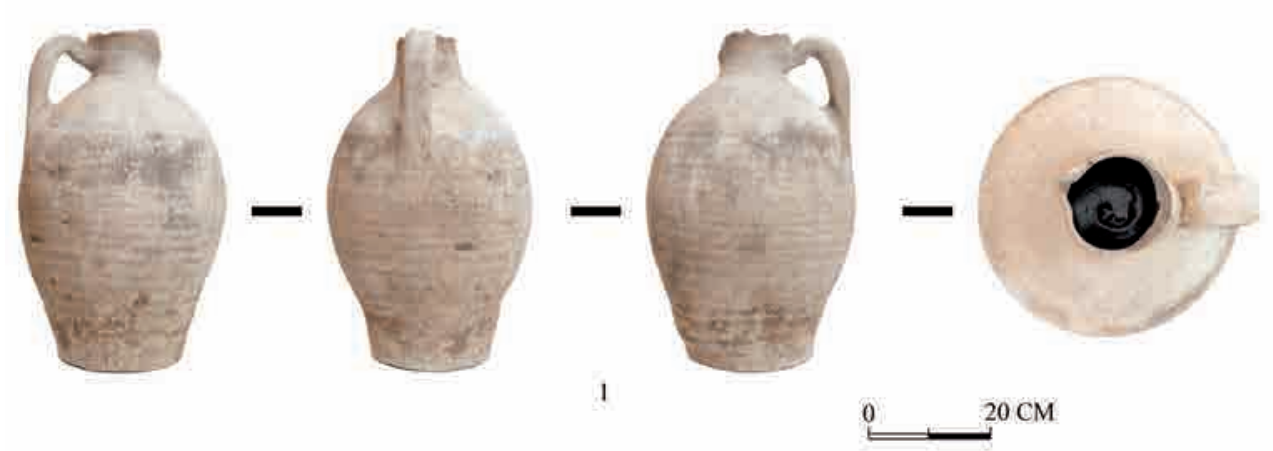

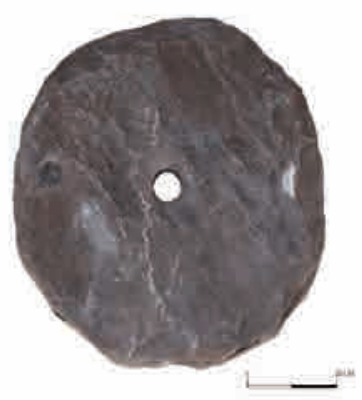

2

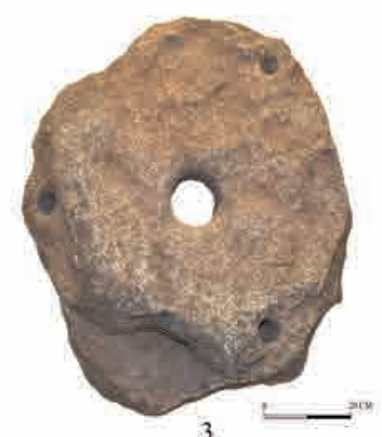

3.

Рис. 3. Городище Бытыгай. Материалы раскопок полевого сезона 2021 г.: 1 - керамический сосуд с жидкостью; 2-3 - каменные жернова; 4 - каменная мотыга 3-сур. Бытығай қаласы. 2021 жылғы далалық маусымдағы қазба материалдары:

1 - құйылған сұйықтығымен қыш ыдыс; 2-3 - диірмен тасы; 4 - тас кетпен

Fig. 3. Bytygay settlement. Excavation materials for the 2021 field season: 1 - a ceramic vessel with a liquid; $2-3$ - stone millstones; 4 - stone hoe 
без глазури и один тип орнаментированный, покрытый глазурью:

1 тип. Кирпичи размерами $22 \times 22 \times 5$ см; они были использованы преимущественно при кладке пола (рис. 4, 1).

2 тип. Кирпичи размерами $22 \times 22 \times 4$ см. Строительный материал данного формата использовался при возведении стен.

3 тип. Обожженные кирпичи $35 \times 22 \times 5$ см. Найдены в нижних рядах кладки стен (рис. 4, 2).
4 тип. Кирпичи прямоугольной формы $22 \times 11 \times 4$ см. Целые и обломки кирпичей такой величины собраны в портальной части мавзолея.

5 тип. Кирпичи размерами $20 \times 10 \times 5$ см. Найдены в основном при исследовании производственного центра. Подобными кирпичами полностью возведены межкомнатные стены.

6 тип. Кирпичи размерами $12 \times 12 \times 4$ см. Собраны у входа в производственный центр, их использовали
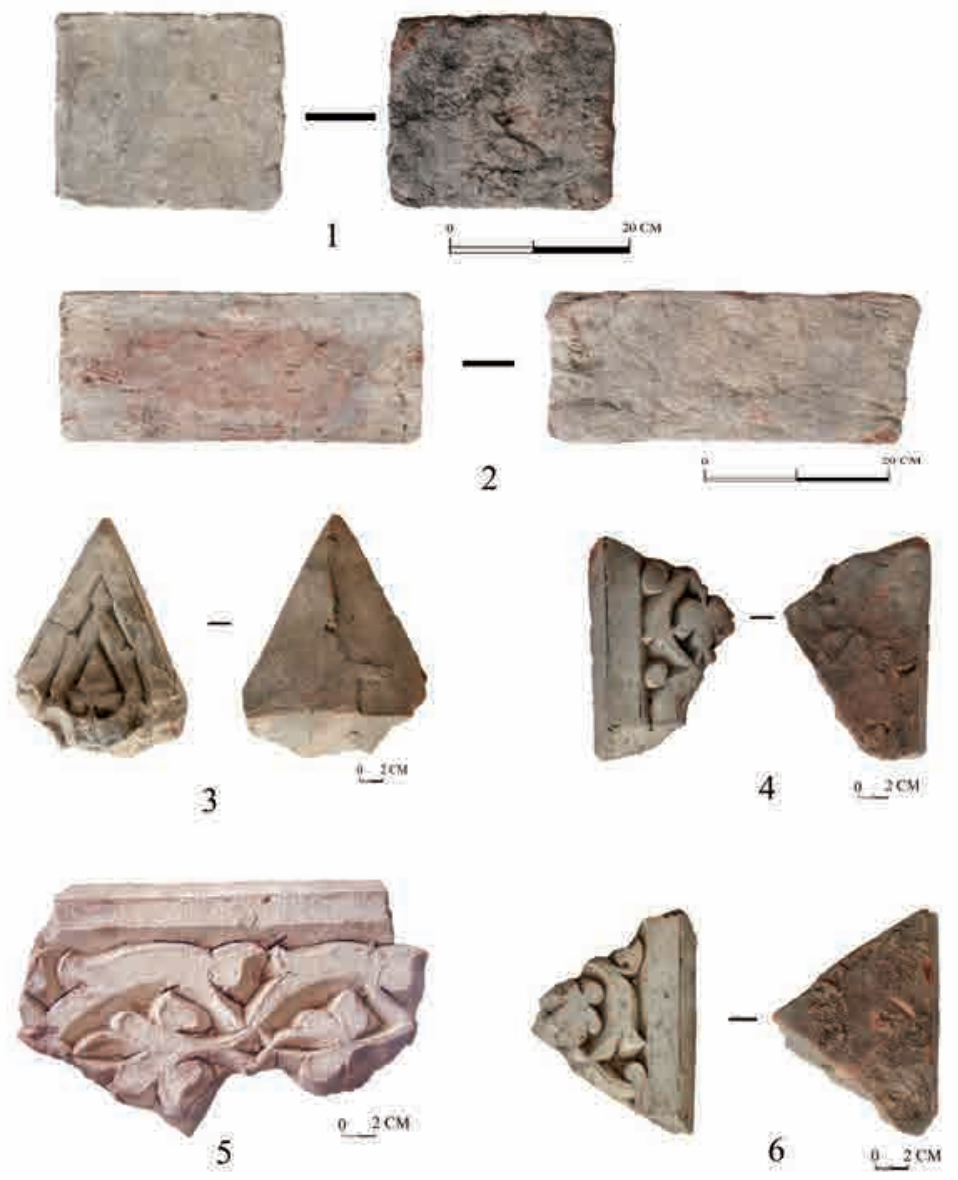

Рис. 4. Городище Бытыгай. Обожженные и терракотовые кирпичи из раскопок 2021 г.

4-сур. Бытығай қаласы. 2021 жылғы қазбадан алынған күйдірілген және терракотты кірпіш

Fig. 4. Bytygay settlement. Fired and terracotta bricks from the 2021 excavation 
при обкладке лестничных проемов. Они найдены in situ на лестничных ступеньках.

7 тип. Облицовочная плитка с растительным орнаментом в виде пятилепесткового цветка со стеблем. Плитки изогнутые, без покрытия глазурью. Средняя ширина по основанию равна 13-15 см, высота по центральной части составляет 9-11 см, толщина 5 см. Данный тип плиток использовался для оформления портала и фасада мавзолеев (рис. 4,3 ).

8 тип и подтипы. Плитки, покрытые глазурью, разных размеров и форм. Архитектурно-отделочный материал отличается только по цвету. На территории городища собраны плитки, покрытые глазурью с бирюзовой, синей и светлой поливой (рис. 3).

В южной части производственного цеха найдены жернова, выполненные из гранита (рис. 2, 7). Диаметр основного (центрального) отверстия жернова составляет 8 см, диаметр места, предназначенного для закрепления деревянной ручки, - 5 см. Нижняя часть жернова гладкая, с различными углублениями и со следами сработанности на рабочей поверхности (рис. 5, 2). Вторая часть жернова толщиной 10 см, диаметр центрального отверстия $-0,75$ см. По краям имеет три отверстия, каждое диаметром 6 см. Данные углубления были предназначены для установки деревянных ручек (рис. 5,3 ). Массивные жернова использовались для измельчения кварцита.

Помимо этого, на территории раскопа обнаружены каменные мотыги. Первая длиной 8 см, шириной 5,5 см. Верхняя рабочая часть $5,5 \times 4,5$ см, толщина $-0,7$ см. Вторая - длиной $22 \mathrm{~cm}$, шириной $12 \mathrm{~cm}$, тол- щиной 5 см. Рабочая зона $11 \times 16 \mathrm{cm,}$ ручка - $13 \times 9$ см (рис. 4,4 ). Основное функциональное предназначение мотыг - это дробление и измельчение сырья, необходимого для производства кирпичей.

Историко-культурная принадлежность и хронология

Одной из архитектурнокомпозиционных и стилистических особенностей при строительстве городов, селений и поминально-культовых сооружений в средние века является использование декоративных, орнаментированных терракотовых кирпичей. В архитектуре Средней Азии первой половины XIV в. активно применяются поливные, резные и тисненные терракотовые плитки. Также быстрыми темпами развивается изготовление керамических изделий в технике расписной майолики и применение такого декоративного покрытия для стен дома, как мозаичная штукатурка на силикатной основе [Пугаченкова 1976]. Кирпичи покрывались легкоплавкой цветной прозрачной глазурью и непрозрачной эмалью. Поверхность сталактитов, изготовленных из керамической массы, также покрывалась слоем глазури. Найденные на территории городища Бытыгай архитектурно-отделочные материалы подразделяются на три типа: кирпичи с орнаментом и глазурью; кирпичи с орнаментом и без глазури; плитки, покрытые глазурью.

Строительные материалы определенных форм и размеров, терракотовые кирпичи, плитки, покрытые глазурью, при изучении средневековых памятников являются основными индикаторами историко-культурных процессов. Утверждение и соблюде- 

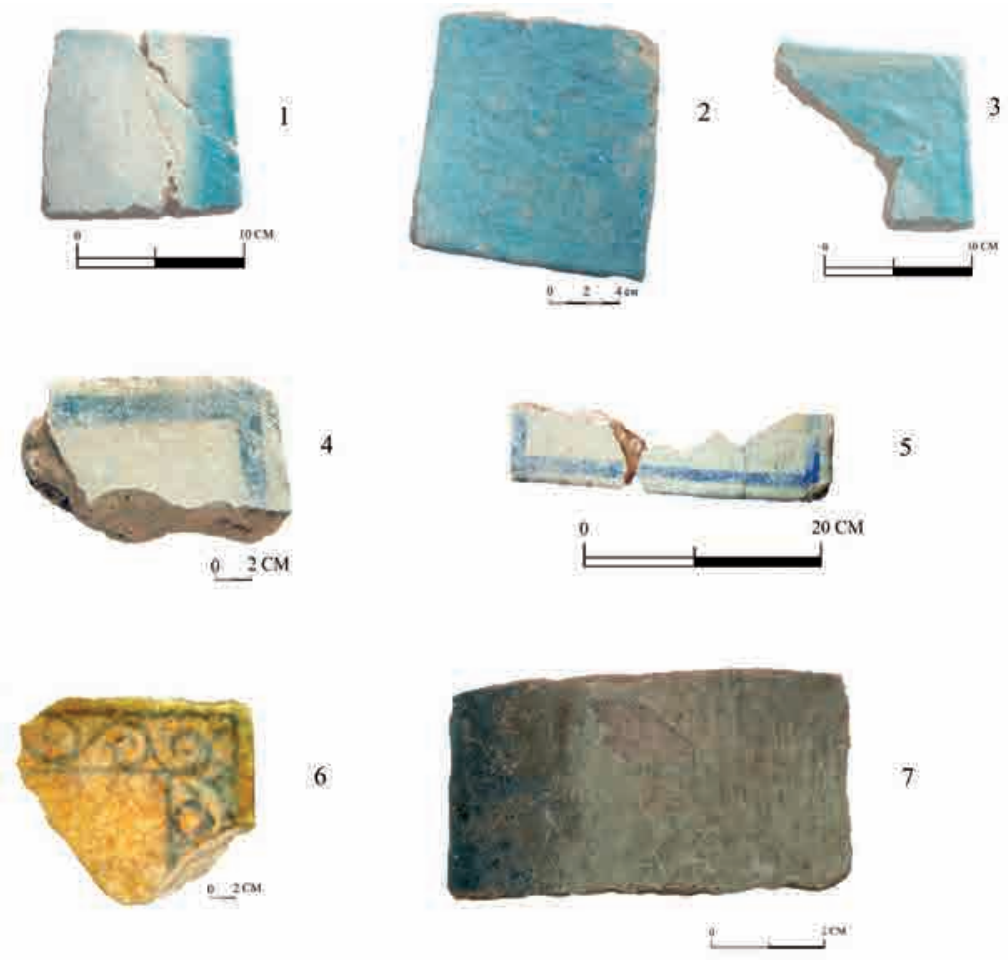

Рис. 5. Городище Бытыгай. Обожженные кирпичи с глазурью (материалы из архива М. Семби)

5-сур. Бытығай қаласы. Сырланған күйдірілген кірпіш (М. Сембі архивінен алынған материалдар)

Fig. 5. Bytygay settlement. Fired bricks with glaze (materials from the archive of M. Sembi)

ние определенных стандартов в строительном деле, организация сложных технологических производств говорят нам о сложении и функционировании государственных систем в ТенгизКоргалжинском регионе.

На основе анализа вышеперечисленных археологических фактов городище Бытыгай можно предварительно датировать XIV-XV вв. и рассматривать поселение как один из важных экономических и политических центров в Степи в средние века.

Самые ближайшие аналогии материалам городища Бытыгай демонстрирует мавзолей Жанибек-Шалкар, расположенный в 17 км восточнее. В результате исследования мавзолея зафиксированы и собраны такие же стандартные кирпичи и архитектурноотделочные материалы, покрытые глазурью бирюзового цвета. Мавзолей Жанибек-Шалкар датирован XIV-XV вв. [Ярыгин 2011: 388]. Материалы городища хорошо коррелируются с материалами средневековой городской культуры на территории Казахстана. Их можно сопоставить со средневековыми памятниками, расположенными в Улытауском регионе, в частности, с памятником Жоши ордасы. Археологическое изыскание на Жоши ордасы, проведенное Ж.Е. Смаиловым, позволило обнаружить станковую керамику высокого качества, обожженные кирпичи, покрытые 
глазурью голубого цвета, а также кирпичи с определенными знаками. Стены сооружения воздвигались из кирпичей. От входной двери начинался тамбур - своеобразный коридор, в нем расчищены лестничные ступеньки. В помещениях расчищены печи каминного типа, тандыры. Памятник датирован XIII-XV вв. [Егинбайулы 2001: 98-106; Смаилов 2015: 50-54].

Планиграфия и функция городища Бытыгай сопоставима с городищами, расположенными на территории центральной части Сарыарки, такими как Болган ана и Белен ана [Маргулан 1950; Смаилов 2015: 20]. Жизнь в этих городищах процветала, этому способствовало бурное развитие торговли с присырдарьинскими и среднеазиатскими городами. Данные городища выполняли функцию административно-торговых центров, осуществляли таможенный контроль, а также были заняты в административном регулировании процессов летовок (джайлау) и зимовок (кыстау) скотоводческих хозяйств. Как и в Бытыгае, в окрестностях этих городищ возведены мавзолеи и расположены крупные некрополи.

\section{Заключение}

Впервые на территории средневекового городища Бытыгай полностью исследован производственный центр. Археологические данные показали, что здесь в средние века осуществлялся полный технологический цикл, проходивший в определенной последовательности: разработка ме- сторождения сырья (ганча); предварительная обработка сырья с использованием каменных жерновов; гашение сырья в специальной емкости; плавка сырья в специальной печи для получения глазури; обжиг кирпичей в печи. Наличие большого количества бракованных предметов и шлаков свидетельствует о его длительном функционировании. Находки резной терракоты, кирпичи, покрытые глазурью, свидетельствуют о существовании целого поколения умельцев, живших в средневековую эпоху и являвшихся признанными мастерами средневекового зодчества.

Обнаруженные артефакты указывают на существование в далеком прошлом в Тенгиз-Коргалжинском регионе процветающего города. Все строительные работы выполнены согласно определенному и установленному стандарту, что свидетельствует о наличии архитектурного плана и роли, которую играл город в средневековой жизни Сарыарки. С развитием городской культуры связаны важные исторические процессы этого периода, начиная с объединения казахских племен до создания государственности. По данным археологии, в XIV$\mathrm{XV}$ вв. Бытыгай был политическим, экономическим и производственным центром. Дальнейшие исследования и накопление нового материала позволит по-новому взглянуть на нерешенные научные проблемы средневековой истории Казахстана и способствуют их решению.

\section{ЛИТЕРАТУРА}

1. Архивные отчеты ЦКАЭ-1974 // Каталог. Бытыгай, Сылу-Там (историкоархеологические материалы). Алма-Ата, 1975. 
2. Броневский С.Б. Записки генерал-майора Броневского о киргиз-кайсаках Средней орды. О памятниках древности. В: Отечественные записки. 1830, ч. 43. С. 244-252 // ЦГА РК. Ф. 338, оп. 1, д. 714.

3. Бурбаева С.Б., Сембин М.К., Букешева Г.К. Судьба памятника Бытыгай по исследованиям путешественников // XXVII Международная научно-практическая конференция: «Наука и инновации в XXI веке: актуальные вопросы, открытия и достижения» (г. Пенза, 25 октября 2021 г.). Пенза: МЦНС «Наука и Просвещение», 2021. C. 136-141.

4. Егинбайуль Ж. Археологические исследования комплекса Жошы-хана // Отан тарихы. 2001. № 2. С. 98-106.

5. Елеуов М.Е. Ақмола обылысындағы зеттеулер // Сарыарқа мен Шу, Талас, Келес өңірлерінің ортағасырлық қалалары, мекендері және керуен жолдары. Ғылыми-зерттеу жұмысы туралы Есеп. Астана, 2000. 7-18-бб.

6. Маргулан А.Х. Из истории городов и строительного искусства древнего Казахстана. Алма-Ата: Изд-во АН КазССР, 1950. 122 с.

7. Пугаченкова Г.А. Зодчество Центральной Азии. XV век. Ведущие тенденции и черты. Ташкент: Издательство литературы и искусства. 1976. 116 с.

8. Свод памятников истории и культуры Республики Казахстан. Акмолинская область. Алматы: Аруна, 2009. 568 с.

9.СембинМ.К. МавзолеиБотагай,Сырлы-Там,Сулу-Там(историко-археологические материалы). Отчет проектно-сметного отдела Научно-реставрационного отдела Министерства культуры КазССР. Алма-Ата, 1975. 80 с.

10. Семби M.K. Мавзолей Ботагай - памятник средневековой казахской архитектуры (краткая история исследования) // Булантинская битва: история исследований. Улытау: Национальный историко-культурный и природный заповедник-музей «Улытау», 2015. С. $150-153$.

11. Смаилов Ж.Е. Памятники археологии западной Сарыарки (Средневековые городища и поселения). Караганда: Изд-во Tengri ltd, 2015. 142 с.

12. Шангин И.П. Извлечение из описания экспедиции, бывшей в Киргизской степи в 1816 году / Сибирский Вестник. 1820. Ч. 11. 114 с.

13. Ярыгин С.A. Исследования мавзолея XV века на озере Жанибек-Шалкар // Маргулановские чтения-2011 (г. Астана, 20-22 апреля 2011 г.) / гл. ред. М.К. Хабдулина. Астана: ЕНУ им. Л.Н. Гумилева, 2011. С. 384-391.

\section{REFERENCES}

1. Arkhivnyye otchety TSKAE-1974 (Archival reports TsKAE-1974). Katalog. Bytygay, Sylu-Tam (istoriko-arkheologicheskiye materialy). 1975. Alma-Ata (in Russian).

2. Bronevskiy, S .B. 1830. In: Tsentralnyi gosudarstvennyi arkhiv Respubliki Kazakhstan. F. 338, op. 1, d. 714, 1. 244-252 (in Russian).

3. Burbayeva, S. B., Sembin, M. K., Bukesheva, G. K. 2021. In: XXVII Mezhdunarodnaya nauchno-prakticheskaya konferentsiya «Nauka i innovatsii v XXI veke» (XXVII International Scientific and Practical Conference: "Science and Innovation in the XXI century"). Penza: "Nauka i Prosveshcheniye" Publ., 136-141 (in Russian).

4. Yeginbayuly, Zh. 2001. In: Otan tarikhy, 2, 98-106 (in Russian).

5. Eleuov, M. E. 2000. Aķmola obylysyndazy zetteuler (Research in Akmola region). Astana, 7-18 (in Kazakh).

6. Margulan, A. Kh. 1950. Iz istorii gorodov i stroitelnogo iskusstva drevnego Kazahstana (From the history of cities and building art of ancient Kazakhstan). Alma-Ata: Akademiya nauk KazSSR (in Russian).

7. Pugachenkova, G. A. 1976. Zodchestvo Tsentralnoy Azii. XV vek. Vedushchie tendentsii $i$ cherty (The architecture of Central Asia. XV century. Leading trends and traits). Tashkent: Izdatelstvo literatury $\mathrm{i}$ iskusstva (in Russian). 
8. Svod pamyatnikov istorii i kultury Respubliki Kazahstan. Akmolinskaya oblast (Collection of monuments of history and culture of the Republic of Kazakhstan. Akmola region). 2009. Almaty: "Aruna" Publ. (in Russian).

9. Sembin, M. K. 1974. Mavzoley Botagay, Syrly-Tam, Sulu-Tam (istoriko-arheologicheskie materialy) (The mausoleums of Botagay, Syrly-Tam, Sulu-Tam (historical and archaeological materials)). Alma-Ata (in Russian).

10. Sembi, M. K. 2015. In: Bulantinskaya bitva: istoriya issledovaniy (The Battle of Boulantine: A History of Research). Ulytau: zapovednik-museum "Ulytau", 150-153 (in Russian).

11. Smailov, Zh. E. 2015. Pamyatniki arheologii zapadnoy Saryarki (Srednevekovye gorodishcha i poseleniya) (Archeological monuments of western Saryarka (Medieval settlements and settlements)). Karaganda: Tengri ltd. (in Russian).

12. Shangin, I. P. 1820. In: Sibirskiy Vestnik. 1820. Chast 11 (in Russian).

13. Yarygin, S. A. 2011. In: Khabdulina, M. K. (ed.). Margulan readings-2011. Astana: L.N. Gumilyov Eurasian National University, 384-391 (in Russian).

Мүдделер қақтығысы туралы ақпаратты ашу. Автор мүдделер қақтығысының жоқтығын мәлімдейді.

/ Раскрытие информации о конфликте интересов. Автор заявляет об отсутствии конфликта интересов.

/ Disclosure of conflict of interest information. The author claims no conflict of interest.

Мақала туралы ақпарат / Информация о статье / Information about the article.

Редакцияға түсті / Поступила в редакцию / Entered the editorial office: 21.10.2021.

Рецензенттер мақұлдаған / Одобрено рецензентами / Approved by reviewers: 30.10.2021.

Жариялауға қабылданды / Принята к публикации / Accepted for publication: 30.10.2021. 